\title{
Filamentous Fungi and Yeasts Associated with Mites Phoretic on Ips typographus in Eastern Finland
}

\author{
Riikka Linnakoski ${ }^{1, *(\mathbb{D})}$, Ilmeini Lasarov ${ }^{2}$, Pyry Veteli ${ }^{1}$, Olli-Pekka Tikkanen ${ }^{2}$, Heli Viiri ${ }^{3}{ }^{(0)}$, Tuula Jyske ${ }^{1}$, \\ Risto Kasanen ${ }^{4}$, Tuan A. Duong ${ }^{5}$ and Michael J. Wingfield ${ }^{5}$ \\ 1 Natural Resources Institute Finland (Luke), FI-00790 Helsinki, Finland; pyry.veteli@gmail.com (P.V.); \\ tuula.jyske@luke.fi (T.J.) \\ 2 School of Forest Sciences, University of Eastern Finland, FI-80100 Joensuu, Finland; \\ ilmeini.lasarov@gmail.com (I.L.); olli-pekka.tikkanen@uef.fi (O.-P.T.) \\ 3 UPM Kymmene Forestry and Wood Processing, FI-33101 Tampere, Finland; heli.viiri@upm.com \\ 4 Department of Forest Sciences, University of Helsinki, FI-00014 Helsinki, Finland; risto.kasanen@helsinki.fi \\ 5 Department of Biochemistry, Genetics and Microbiology, Forestry and Agricultural Biotechnology \\ Institute (FABI), University of Pretoria, Pretoria 0083, South Africa; tuan.duong@up.ac.za (T.A.D.); \\ mike.wingfield@fabi.up.ac.za (M.J.W.) \\ * Correspondence: riikka.linnakoski@luke.fi; Tel.: +358-29-532-2289
}

check for updates

Citation: Linnakoski, R.; Lasarov, I.; Veteli, P.; Tikkanen, O.-P.; Viiri, H.; Jyske, T.; Kasanen, R.; Duong, T.A.; Wingfield, M.J. Filamentous Fungi and Yeasts Associated with Mites Phoretic on Ips typographus in Eastern Finland. Forests 2021, 12, 743. https://doi.org/10.3390/ f12060743

Academic Editor: Nicola Luchi

Received: 1 May 2021

Accepted: 12 May 2021

Published: 4 June 2021

Publisher's Note: MDPI stays neutral with regard to jurisdictional claims in published maps and institutional affiliations.

Copyright: (c) 2021 by the authors. Licensee MDPI, Basel, Switzerland. This article is an open access article distributed under the terms and conditions of the Creative Commons Attribution (CC BY) license (https:/ / creativecommons.org/licenses/by/ $4.0 /)$.

\begin{abstract}
The European spruce bark beetle (Ips typographus) has become a major forest pest in Finland in recent years. The beetle is a well-known vector of mainly ophiostomatoid fungi causing bluestain of timber and pathogens that have the ability to amplify the insect damage. It also vectors other associated organisms, such as phoretic mites. The ecology of these mites remains poorly understood, including their associations with fungi. In this study, we considered filamentous fungi and yeasts associated with mites phoretic on I. typographus. Fungal identifications were based on DNA sequences and phylogenetic analyses of the ITS and/or partial $\beta$-tubulin gene regions. Fifteen fungal species were detected, including eight yeasts and seven filamentous fungi. Eleven percent of the beetles carried mites and of these $74 \%$ carried at least one fungal species. An average of two fungal species were carried per mite. The most commonly found filamentous fungi were Grosmannia penicillata (25\%), Ophiostoma bicolor (19\%), O. ainoae (12\%) and O. brunneolum (12\%). Of the yeast species, the most commonly found was Wickerhamomyces bisporus (47\%). This study is the first to report yeasts associated with I. typographus and its phoretic mites in Finland. Majority of the filamentous fungal species found are those previously reported in association with I. typographus. The results also confirmed that many of the fungal species commonly found on I. typographus are also associated with its phoretic mites. However, the nature of the symbiosis between the mites, beetles and fungal associates remains to be understood.
\end{abstract}

Keywords: boreal forests; fungal diversity; insect-fungus symbiosis; ophiostomatoid fungi; spruce bark beetle; yeasts

\section{Introduction}

The European spruce bark beetle (Ips typographus L.) is a major forest pest in Europe. In recent years, its importance has increased also in the Northern Europe due to changing climate [1,2]. The beetle is a vector of fungi and other microorganisms, such as phoretic mites and nematodes [3-5]. Particularly common fungal associates are ophiostomatoid fungi (Ophiostomatales and Microascales), a polyphyletic group of fungi having morphological and chemical co-adaptations to arthropod dispersal [6,7]. The majority of these fungi are saprophytic species, but some are tree-killing pathogens having the ability to amplify the insect damage.

Fungi associated with I. typographus have been relatively well studied in Europe. Certain species such as Endoconidiophora polonica (Siemaszko) Z.W. de Beer, T.A. Duong \& M.J. Wingfield, Grosmannia penicillata (Grosmann) Goid., Grosmannia europhioides (E.F. Wright \& Cain) 
Zipfel, Z.W. de Beer \& M.J. Wingf. and Ophiostoma bicolor R.W. Davidson \& D.E. Wells are amongst the most frequently found fungi associated with the beetle [8-11]. Although I. typographus and its fungal associates represents one of the most extensively studied examples of bark beetle-fungi interactions, new fungal species discoveries and descriptions are not uncommon [12-14]. Recent studies have reported occurrence of spatial and temporal differences in the fungal species assemblages $[3,10]$ and showing volatile organic compounds influencing the beetle-fungi interactions [6]. Despite these advances, many aspects like multitrophic interactions involving beetles, mites and fungi and factors maintaining these complex interactions remain poorly known [15].

Increasing evidence suggests that bark beetle-associated mites are important vectors of fungi present in beetle galleries [10,16-19]. The mites can carry fungal spores on their bodies or in specialized structures (sporothecae) to new host trees [19]. Some mite species are mycetophagous feeding on fungi; mites can promote mutualistic fungi and increase fungal survival by reducing antagonistic fungi in the bark beetle $[20,21]$.

The vast majority of studies have focused on the diversity of ophiostomatoid fungi associated with I. typographus and to some extent also with its phoretic mites. In contrast, little is known regarding the other fungi involved in these interactions. In addition to ophiostomatoid fungi, yeasts have also been recognized as constant components in bark and ambrosia beetle galleries [22,23] and in the guts of the beetles [24]. Yeasts have most likely been overlooked in majority of the previous collections. Particularly common amongst these yeasts are those in the Ascomycotes that rely on vectors to move to new hosts trees [25].

The aim of the study was to provide baseline knowledge on fungal diversity associated with mites phoretic on I. typographus infesting Picea abies L. in Eastern Finland.

\section{Materials and Methods}

\subsection{Study Area and Collection of Samples}

Wind-felled P. abies trees infested by I. typographus were sampled from June to September 2017 in two spruce-dominated forests in North Karelia province; Kuhasalo (N 62 $34^{\prime} 46^{\prime \prime}$; E29 $44^{\prime} 13^{\prime \prime}$ ) and Rasimäki (N 62 $30^{\prime} 62^{\prime \prime} ;$ E $\left.29^{\circ} 58^{\prime} 27^{\prime \prime}\right)$. Adult living beetles were collected either directly from the galleries (each beetle from a separate gallery, maximum ten beetles from the same tree individual) in Kuhasalo or using Ipsowit ${ }^{\circledR}$ Standard (Witasek PflanzenSchutz GmbH, Feldkirchen in Kärnten, Austria) in Rasimäki pheromone funnel traps that were emptied weekly during the sampling period and stored individually in Eppendorf tubes. To prevent living mite contamination of the mycology laboratory, the beetles were stored at $-20^{\circ} \mathrm{C}$ at least for $24 \mathrm{~h}$ prior to fungal isolations. Beetles were morphologically identified using a dissecting microscope. At the same time, phoretic mites on the beetles were collected individually, crushed with sterilized tools and plated directly onto $2 \%$ malt extract agar (MEA; $2 \%$ malt extract from Biokar Diagnostics, Beauvais, France and 2\% agar from Fisher Scientific, Mexico) in Petri dishes containing $0.05 \mathrm{~g} / \mathrm{L}$ of streptomycin sulphate (Sigma-Aldrich, St. Louis, MO, USA). The plates were incubated in the dark at $25^{\circ} \mathrm{C}$ for $2-4$ weeks and inspected regularly for fungal growth. Emerging mycelium and spore masses (including yeasts) were transferred to fresh MEA plates (without streptomycin) and subcultured until pure cultures were obtained. Occasionally, $2 \%$ water agar was necessary to use to obtain pure cultures. Purified cultures were grouped based on morphological and culture characteristics and at least one isolate from each group was subjected to DNA-based identification. The isolates obtained in this study were deposited in the culture collection (CMW) of the Forestry and Agricultural Biotechnology Institute (FABI), University of Pretoria, South Africa (Table 1). The isolates were also stored in the culture collection of the Natural Resources Institute Finland (Luke), Helsinki, Finland. 
Table 1. Fungal isolates obtained from mites phoretic on Ips typographus in Eastern Finland.

\begin{tabular}{|c|c|c|c|c|c|}
\hline \multirow{2}{*}{ Species } & \multicolumn{2}{|c|}{ Isolate no } & \multirow{2}{*}{ Mite No. } & \multicolumn{2}{|c|}{ GenBank Acc. No. } \\
\hline & Personal $^{1}$ & $\mathrm{CMW}^{2}$ & & ITS & $\beta$-Tubulin \\
\hline \multirow{4}{*}{$\begin{array}{c}\text { Ceratocystiopsis minuta (Siemaszko) H.P. } \\
\text { Upadhyay \& W.B. Kendr. }\end{array}$} & A10-1aba & 51,536 & A7-1d & & MW345787 \\
\hline & $\begin{array}{c}\text { A7-1d } \\
\text { B3-1aab }\end{array}$ & 51,426 & $\begin{array}{l}\text { A7-1 } \\
\text { B3-1 }\end{array}$ & & MW345786 \\
\hline & B3-6balla & 51,448 & B3-6 & & MW345784 \\
\hline & B6-1ebb & 51,350 & B6-1 & & MW345785 \\
\hline \multirow{2}{*}{$\begin{array}{c}\text { Chionosphaera cuniculicola } \mathrm{R} \text {. Kirschner, } \\
\text { Begerow \& Oberw. } \\
\text { Endoconidiophora polonica }\end{array}$} & B1-2aaaa & 51,590 & B1-1 & MW256646 & \\
\hline & $\begin{array}{l}\text { B3-7ab } \\
\text { B5-7ab } \\
\text { B6-2aba } \\
\text { B6-2ac } \\
\text { B6-3ca }\end{array}$ & $\begin{array}{l}51,327 \\
51,463\end{array}$ & $\begin{array}{l}\text { B3-7 } \\
\text { B5-7 } \\
\text { B6-2 } \\
\text { B6-2 } \\
\text { B6-3 }\end{array}$ & $\begin{array}{l}\text { MW256648 } \\
\text { MW256650 } \\
\text { MW256649 } \\
\text { MW256647 }\end{array}$ & \\
\hline \multirow{3}{*}{$\begin{array}{l}\text { Fontanospora fusiramosa Marvanová, Peter J. } \\
\text { Fisher \& Descals } \\
\text { Graphium fimbriisporum } \\
\text { (M. Morelet) K. Jacobs, Kirisits \& M.J. Wingf. }\end{array}$} & $\mathrm{B} 1-1 \mathrm{~b} 2$ & 51,453 & B1-1 & & \\
\hline & A4-2aab & & A4-2 & & \\
\hline & $\begin{array}{l}\text { A6-1ad } \\
\text { A7-2aca } \\
\text { B6-2ad } \\
\text { B6-3cb }\end{array}$ & $\begin{array}{l}51,382 \\
51,389 \\
51,329\end{array}$ & $\begin{array}{l}\text { A6-1 } \\
\text { A7-2 } \\
\text { B6-2 } \\
\text { B6-3 }\end{array}$ & $\begin{array}{l}\text { MW256653 } \\
\text { MW256652 } \\
\text { MW256651 }\end{array}$ & \\
\hline \multirow[t]{11}{*}{ Grosmannia penicillata } & A6-2b & 51,417 & A6-2 & & \\
\hline & $\begin{array}{l}\text { A6-2cbb } \\
\text { A6-3adb }\end{array}$ & 51,432 & $\begin{array}{l}\text { A6-2 } \\
\text { A6-3 }\end{array}$ & & MW345794 \\
\hline & A6-3c & 51,353 & A6-3 & & MW345789 \\
\hline & A9-1cba & 51,412 & A9-1 & & MW345788 \\
\hline & B5-1b & 51,337 & B5-1 & & MW345793 \\
\hline & $\begin{array}{l}\text { B6-1c } \\
\text { B6-1ca }\end{array}$ & 51,338 & $\begin{array}{l}\text { B6-1 } \\
\text { B6-1 }\end{array}$ & & MW345790 \\
\hline & $\begin{array}{l}\text { B6-2b } \\
\text { B6-2c }\end{array}$ & 51,435 & $\begin{array}{l}\text { B6-2 } \\
\text { B6-2 }\end{array}$ & & \\
\hline & B6-2eca & 51,446 & B6-2 & & MW345791 \\
\hline & B5-1dbb & 51,423 & B5-1 & & MW345792 \\
\hline & A10-1b & 51,376 & A10-1 & & MW345795 \\
\hline & $\begin{array}{l}\text { A10-3ada } \\
\text { A6-3da }\end{array}$ & 51,470 & $\begin{array}{c}\text { A10-1 } \\
\text { A6-3 }\end{array}$ & & MW345796 \\
\hline \multirow[t]{2}{*}{$\begin{array}{c}\text { Kuraishia capsulata (Wick.) Y. Yamada, K. } \\
\text { Maeda \& Mikata }\end{array}$} & A4-2аaаa & 51,570 & A4-2 & MW256635 & \\
\hline & G83-1aa & 51,578 & G83 & MW256634 & \\
\hline \multirow{4}{*}{$\begin{array}{c}\text { Kuraishia molischiana } \\
\text { Dlauchy, G. Péter, Tornai-Leh. \& Kurtzman } \\
\text { Nakazawaea sp. }\end{array}$} & B2-3aa & 51,574 & B2-3 & MW256633 & \\
\hline & B8-1aaa & & B8-1 & & \\
\hline & B8-1abb & 51,543 & B8-1 & MW256638 & \\
\hline & B2-3b & 51,542 & B2-3 & MW256639 & \\
\hline \multirow{9}{*}{$\begin{array}{c}\text { Ogataea glucozyma } \\
\text { (Wick.) Y. Yamada, K. Maeda \& Mikata } \\
\text { Ogataea ramenticola } \\
\text { (Kurtzman) Kurtzman \& Robnett } \\
\text { Ophiostoma ainoae } \\
\text { H. Solheim }\end{array}$} & F30-1caa & 51,585 & F30 & MW256636 & \\
\hline & B3-1aaaa & 51,591 & B3-1 & MW256637 & \\
\hline & A4-2aab & 51,342 & A4-2 & & MW345797 \\
\hline & $\mathrm{A} 4-2 \mathrm{~b}-1$ & 51,464 & $\mathrm{~A} 4-2$ & & \\
\hline & A7-2db & 51,361 & A7-2 & & MW345800 \\
\hline & A9-1cbbb & 51,354 & A9-1 & & MW345798 \\
\hline & B6-2ea & 51,459 & B6-2 & & \\
\hline & B6-2ebb & & B6-2 & & \\
\hline & B6-2ecb & 51,341 & B6-2 & & MW345799 \\
\hline
\end{tabular}


Table 1. Cont.

\begin{tabular}{|c|c|c|c|c|c|}
\hline \multirow{2}{*}{ Species } & \multicolumn{2}{|c|}{ Isolate no } & \multirow{2}{*}{ Mite No. } & \multicolumn{2}{|c|}{ GenBank Acc. No. } \\
\hline & Personal $^{1}$ & $\mathrm{CMW}^{2}$ & & ITS & $\beta$-Tubulin \\
\hline \multirow[t]{12}{*}{ Ophiostoma bicolor } & A10-2b & 51,355 & A10-1 & & MW345809 \\
\hline & A7-2ab & 51,367 & A7-2 & & MW345806 \\
\hline & $A 7-2 b$ & 51,364 & A7-2 & & \\
\hline & A7-2da & 51,462 & A7-2 & & \\
\hline & B1-1d & 51,442 & B1-1 & & MW345805 \\
\hline & B3-1aba & & B3-1 & & \\
\hline & B3-1b & 51,352 & B3-1 & & MW345804 \\
\hline & B3-1d & 51,425 & B3-1 & & \\
\hline & B3-7ad & 51,343 & B3-7 & & MW345807 \\
\hline & A10-1dac & 51,456 & A10-1 & & \\
\hline & $\mathrm{A} 10-1 \mathrm{db}$ & 51,427 & A10-1 & & \\
\hline & $\begin{array}{l}\text { B3-7ac } \\
\text { A7-1b }\end{array}$ & & $\begin{array}{l}\text { B3-7 } \\
\text { A7-1 }\end{array}$ & & MW345808 \\
\hline \multirow{7}{*}{$\begin{array}{l}\text { Ophiostoma brunneolum } \\
\text { Linnak., Z.W. de Beer \& M.J. Wingf. }\end{array}$} & B1-3ab & & B1-3 & & \\
\hline & B1-3gab & 51,328 & B1-3 & & \\
\hline & B1-3gbb & 51,371 & B1-3 & & MW345801 \\
\hline & B3-7cb & 51,454 & $\begin{array}{l}\text { B3-7 } \\
\text { B8-1 }\end{array}$ & & MW345802 \\
\hline & $\begin{array}{l}\text { B8-1ac } \\
\text { B8-2ba }\end{array}$ & $\begin{array}{l}51,454 \\
51,422\end{array}$ & $\begin{array}{l}\text { B8-1 } \\
\text { B8-2 }\end{array}$ & & MW345803 \\
\hline & $\mathrm{B} 8-2 \mathrm{bb}$ & 51,346 & B8-2 & & \\
\hline & B8-cb & 51,375 & B8-2 & & \\
\hline \multirow{7}{*}{$\begin{array}{c}\text { Wickerhamomyces bisporus } \\
\text { (O. Beck) Kurtzman, Robnett \& } \\
\text { Basehoar-Powers }\end{array}$} & & & & & \\
\hline & A6-1aaba & 51,547 & A6-1 & MW256640 & \\
\hline & A6-3aаa & 51,544 & A6-3 & MW256641 & \\
\hline & $\begin{array}{c}\text { A7-2aaa } \\
\text { B1-1a }\end{array}$ & 51,575 & $\begin{array}{l}\text { A7-2 } \\
\text { B1-1 }\end{array}$ & MW256644 & \\
\hline & B1-3aаa & 51,584 & B1-1 & MW256642 & \\
\hline & B2-1aaa & 51,581 & B2-1 & MW256645 & \\
\hline & B2-2аaа & 51,589 & B2-2 & MW256643 & \\
\hline
\end{tabular}

${ }^{1}$ Personal collection stored at the culture collection of the Natural Resources Institute Finland (Luke), Helsinki, Finland; ${ }^{2} \mathrm{CMW}$ : Culture Collection of the Forestry and Agricultural Biotechnology Institute (FABI), University of Pretoria, Pretoria, South Africa.

\subsection{DNA Extraction, PCR and Sequencing}

Prior to DNA extraction, the fungi were grown in $5 \mathrm{~mL}$ of liquid culture medium $(2 \%$ malt extract and $0.5 \%$ yeast extract from Biolab, Midrand, South Africa) in $20 \mathrm{~mL}$ glass vials, for $24 \mathrm{~h}$ with shaking (120 rpm). The fungal tissues were then transferred into $1.5 \mathrm{~mL}$ Eppendorf tubes and freeze-dried. The tubes were snap-frozen in liquid nitrogen and the mycelium was ground into fine powder using micro pestles. DNA was extracted from grounded mycelium powder following the method as described by [10].

The internal transcribed spacer gene (ITS) regions including the $5.8 \mathrm{~S}$ gene and in some cases the partial beta-tubulin (BT) gene were amplified and sequenced. The primers used for PCR amplification and sequencing were ITS1-F [26] and ITS4 [27] for the ITS region and T10 [28] for the BT region. The reaction mixture contained $0.2 \mu \mathrm{L}$ of KAPA Taq DNA Polymerase ( $5 \mathrm{U} / \mu \mathrm{L})$ (Kapa Biosystems, Cape Town, South Africa), $2.5 \mu \mathrm{L}$ of MyTaq ${ }^{\mathrm{TM}}$ Reaction Buffer $(5 \times), 2.5 \mu \mathrm{L}$ of dNTPs $(10 \mathrm{mM}), 0.5 \mu \mathrm{L}$ of $50 \mathrm{mM} \mathrm{MgCl}_{2}$ and $0.50 \mu \mathrm{L}$ of each primer (10 mM stock concentration), $2 \mu \mathrm{L}$ fungal genomic DNA and PCR graded water to the final volume of $25 \mu \mathrm{L}$. PCR amplifications were performed using the following conditions: denaturation at $95^{\circ} \mathrm{C}$ for $5 \mathrm{~min}$, followed by 35 cycles of $30 \mathrm{~s}$ at $94{ }^{\circ} \mathrm{C}, 30 \mathrm{~s}$ at $55^{\circ} \mathrm{C}$ and $1 \mathrm{~min}$ at $72{ }^{\circ} \mathrm{C}$ and a final extension at $72{ }^{\circ} \mathrm{C}$ for $10 \mathrm{~min}$. An aliquot of $4 \mu \mathrm{L}$ of each PCR product was stained with $1 \mu \mathrm{L}$ of $6 \times$ Orange DNA Loading Dye (Thermo Fisher Scientific Baltics UAB, Vilnius, Lithuania), run on $2 \%$ agarose gel at $90 \mathrm{~V}$ along with a O'GeneRuler 100 bp Plus DNA Ladder (Thermo Fisher Scientific Baltics UAB, Vilnius, Lithuania), stained with GelRed (Biotium, Hayward, USA) and visualised with a Gel Doc EZ Imager (Bio-Rad Laboratories, Hercules, CA, USA)). Amplified PCR products were 
purified using the EXO-SAP (Exonuclease I-Shrimp Alkaline Phosphatase, Thermo Fisher Scientific, Waltham, MA, USA) protocol.

The same primers used for PCR amplification were also used for sequencing PCR except that Bt2a primer [29] was used instead of T10 primer for sequencing of BT products. The sequencing reactions consisted of $0.5 \mu \mathrm{L}$ of BigDye ${ }^{\circledR}$ Terminator v3.1 Ready Reaction mixture (Perkin-Elmer Applied Biosystems, Warrington, UK), $2.1 \mu \mathrm{L}$ of sequencing buffer, $1 \mu \mathrm{L}$ of either the forward or reverse primer ( $10 \mathrm{mM}$ stock concentration), $1 \mu \mathrm{L}$ of the purified PCR product and PCR grade water to the final volume of $12 \mu \mathrm{L}$. The thermal cycling conditions were: 25 cycles of $10 \mathrm{~s}$ at $96^{\circ} \mathrm{C}, 5 \mathrm{~s}$ at $52{ }^{\circ} \mathrm{C}$ and $4 \mathrm{~min}$ at $60^{\circ} \mathrm{C}$. Sequencing products were then cleaned using ethanol/sodium acetate precipitation. Sequencing fragment analysis was conducted on an ABI Prism 3100 Genetic Analyzer (Applied Biosystems, Foster City, CA, USA) at the DNA Sequencing Facility of the Forestry and Agricultural Biotechnology Institute (FABI), University of Pretoria.

\subsection{Sequence Analyses and Fungal Identification}

Consensus sequences were assembled with the Geneious R6 (Biomatters Ltd., Auckland, New Zealand), after which preliminary identification of the isolates was performed using the BLAST searches in GenBank (http:/ /www.ncbi.nlm.nih.gov (accessed on March 2019)) applying a megablast algorithm. ITS and BT data sets for the different genera or species complexes including type sequences (when available) of closely related species and sequences from different geographical origins to show relationships with other geographic isolates of the same species, were compiled with MEGA v.7 [30]. The data sets were aligned using the online version of MAFFT v.7 [31] with the automatic option of selecting the most suitable multiple alignment strategy for each data set.

Three phylogenetic methods were applied: maximum likelihood (ML), maximum parsimony (MP) and Bayesian inference (BI). ML was performed with the online version of PhyML 3.0 [32], using automatic model selection by SMS [33] and Akaike information criterion (AIC) [34]. Branch support was estimated with Approximate Likelihood-ratio Test (aLRT) [35]. MP analyses were conducted using PAUP v.4.0a164 [36]. Gaps and missing data were excluded in the MP analyses. BI analyses based on a Markov Chain Monte Carlo (MCMC) simulation were carried out with MrBayes v.3.2.2 [37] with bestfitting evolutionary model determined using MrModeltest 2.3 [38] based on the Akaike Information Criterion (AIC). The MCMC chains were run for five million generations using a sample frequency of 100 (resulting in 50,000 trees). Burn-in values were determined for the respective data sets and all trees sampled during the burn-in phase having were discarded. The resulting majority trees were viewed with MEGA v.7 [30] or FigTree v.1.4.3 [39] and post-edited with Adobe Illustrator CC 2018 (Adobe Inc., San Jose, CA, USA).

\section{Results}

\subsection{Collection of Beetles and Mites}

In total, 180 (60 from the galleries and 120 from the pheromone traps) living adults I. typographus beetles were collected and inspected for the presence of phoretic mites. Thirty-nine phoretic mites were found, of which seven were nymphs. Eleven percent of the beetles carried mites. When phoretic mites were present, the number per individual beetle ranged between 1-7 and an average of two mites were carried per beetle. The majority of the phoretic mites were found attached on the elytral declivity surface $(49 \%)$ or ventral surface between the first pair of legs (33\%). Based on morphological identification the mites were species of Uropodina (Acari: Mesostigmata).

\subsection{Isolation and Identification of Fungi}

At least one fungal species was isolated from $87 \%$ of the collected mites. The number of fungal species per individual mite ranged between 1-4, with an average of two fungal species carried per mite. In total, 145 fungal isolates were obtained in this study. Of these 75 isolates, representing the different morphological groups, were subjected for 
DNA sequencing (Table 1). The amplified DNA fragments were approximately 600 and $500 \mathrm{bp}$ long for the ITS region and for the partial BT, respectively. The preliminary BLAST analyses identified the filamentous fungi as members of Ophiostomatales and Microascales (Ascomycota). Most of the yeasts were Ascomycetes, only one Basidiomycete yeast was isolated.

The identities of the fungal species were further confirmed by phylogenetic analysis (Figures 1-8). The filamentous fungi included in total seven species, which included three Ophiostoma sensu lato, one Leptographium s. lat. species (Ophiostomatales) (Figures 1-3) and three species of Microascales (Figures 4-6). The ascomycetous yeast species included six species of Saccharomycetales (Figure 7) and a single yeast-like species of uncertain taxonomic placement (not included in phylogenetic analysis). The single basidiomycetous yeast-like fungus resided in the Agaricostilbales (Figure 8).

\subsection{Ophiostomatales}

The Ophiostoma spp. resided in two species complexes, Ophiostoma ips (Figure 1) and Ophiostoma clavatum (Figure 2). Analysis of BT data set confirmed that isolates residing in the O. ips species complex represented O. bicolor (Figure 1). A total of 16 isolates belonged in the O. clavatum complex (Figure 2). These included Ophiostoma brunneolum and Ophiostoma ainoae isolates (Table 1). The O. ainoae isolates grouped with the ex-type isolate of $O$. ainoae based on the BT data. There was variation amongst the O. brunneolum isolates sequences, but also they formed a distinct clade together with the ex-type isolate of this species.

The isolates in the Leptographium s. lat. resided in the G. penicillata species complex (Figure 3). All the isolates (in total 14) formed a clade with G. penicillata based on BT data. The sequences were most similar to other previously originating from Finland, as well as from China and Austria. The ex-type isolate of G. penicillata had 3-4 bp differences with the isolates obtained in this study. It also groups with the ex-type sequence of Grosmannia fenglinhense R. Chang, Z.W. de Beer \& M.J. Wingf, but this seems to be a typo in the original publication by [3], where the GenBank number MH124324 is indicated to be the BT sequence for G. fenglinhense, but in the GenBank the identification is provided as G. penicillata.

\subsection{Microascales}

The isolates belonging to Microascales were identified as species of Ceratocystiopsis, Endoconidiophora and Graphium (Figures 4-6). Based on the BT sequences analysis, the Ceratocystiopsis isolates included two cryptic species that grouped within Cop. minuta complex containing sequences originating from Europe and Japan (Figure 4). The ITS sequence analysis confirmed that the Endoconidiophora isolates represented E. polonica (Figure 5). The sequences obtained in this study were identical to those of the ex-type isolate of that species originating from Poland. The remaining isolates were identified as Graphium fimbriisporum (Figure 6). 


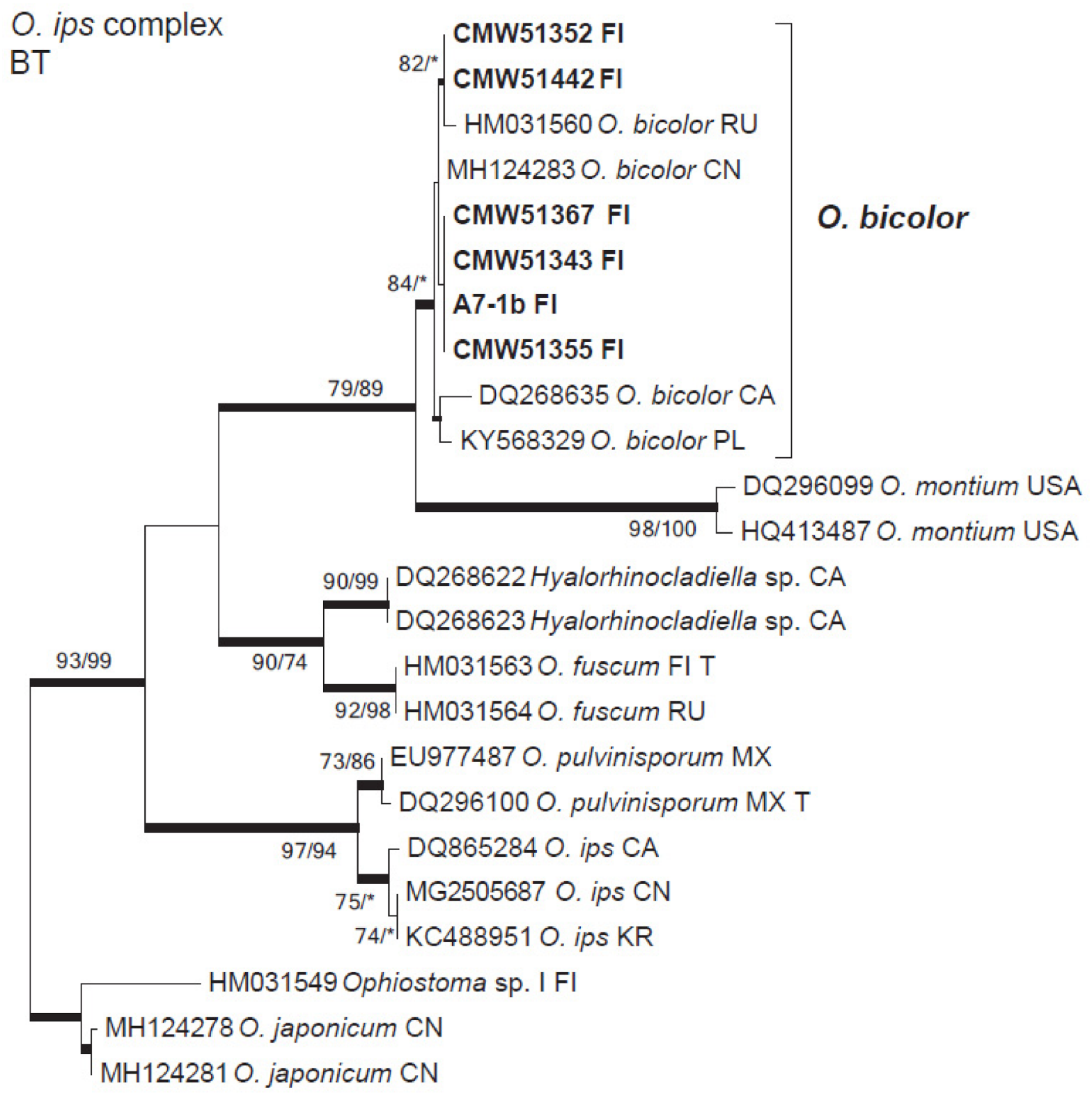

$\stackrel{1}{0.02}$

Figure 1. Phylogenetic tree of Ophiostoma ips species complex obtained from maximum likelihood (ML) analyses of the $\beta$ tubulin data set. Sequences generated in this study are printed in bold type. Bootstrap values above $75 \%$ for ML/maximum parsimony (MP) are presented at the nodes. Posterior probabilities (above 90\%) obtained from Bayesian (BI) are indicated by bold lines at the relevant branching points. ${ }^{*}=$ bootstrap values $<75 \%$. $\mathrm{T}=$ ex-type isolates. Country abbreviations follow ISO 3166 Country Codes. Scale bar $=$ total nucleotide difference between taxa. 


\section{O. clavatum complex}

BT

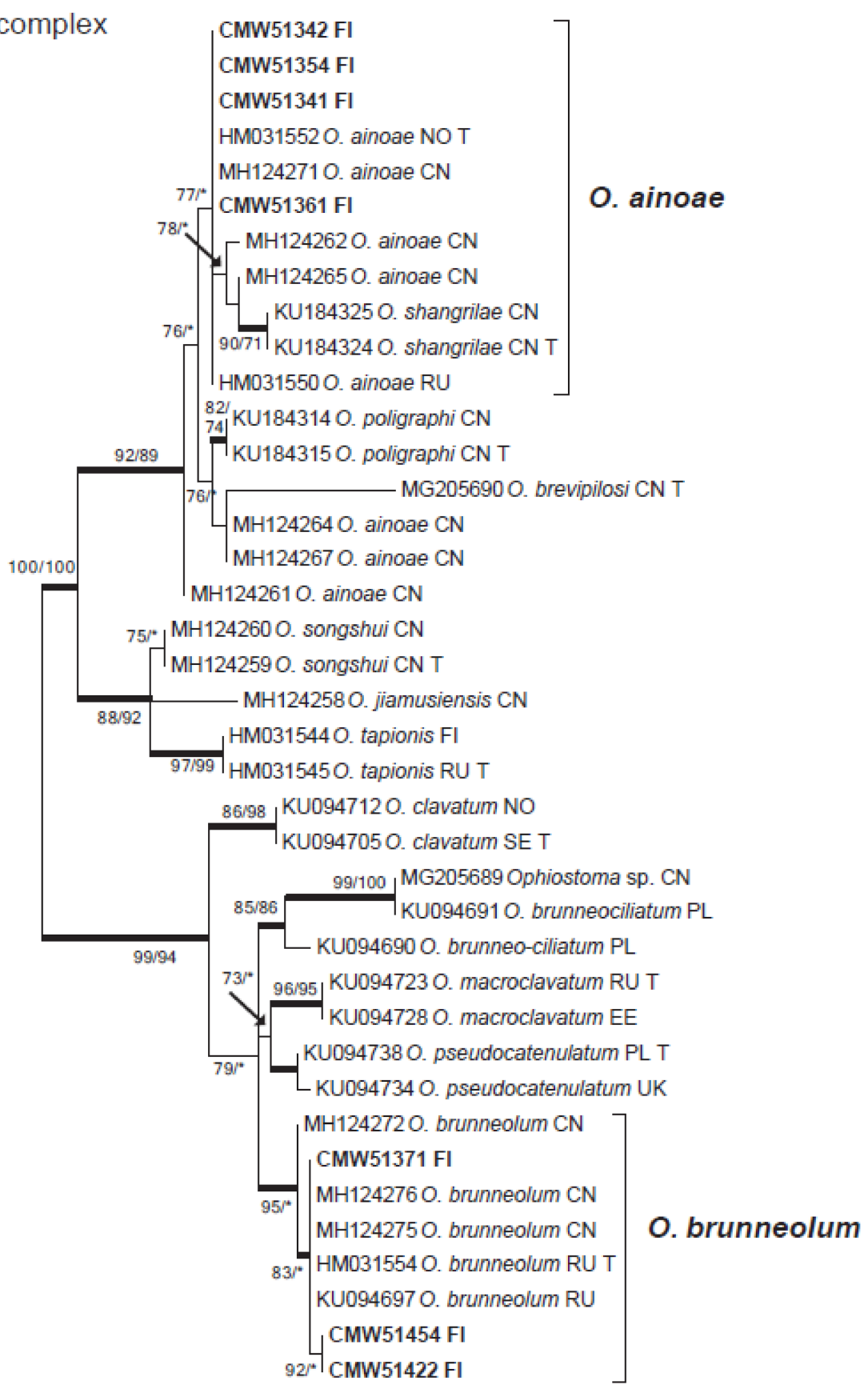

$\stackrel{501}{0.01}$

Figure 2. Phylogenetic tree of Ophiostoma clavatum species complex obtained from maximum likelihood (ML) analyses of the $\beta$-tubulin data set. Sequences generated in this study are printed in bold type. Bootstrap values above $75 \%$ for ML/maximum parsimony (MP) are presented at the nodes. Posterior probabilities (above 90\%) obtained from Bayesian (BI) are indicated by bold lines at the relevant branching points. ${ }^{*}=$ bootstrap values $<75 \%$. T $=$ ex-type isolates. Country abbreviations follow ISO 3166 Country Codes. Scale bar = total nucleotide difference between taxa. 


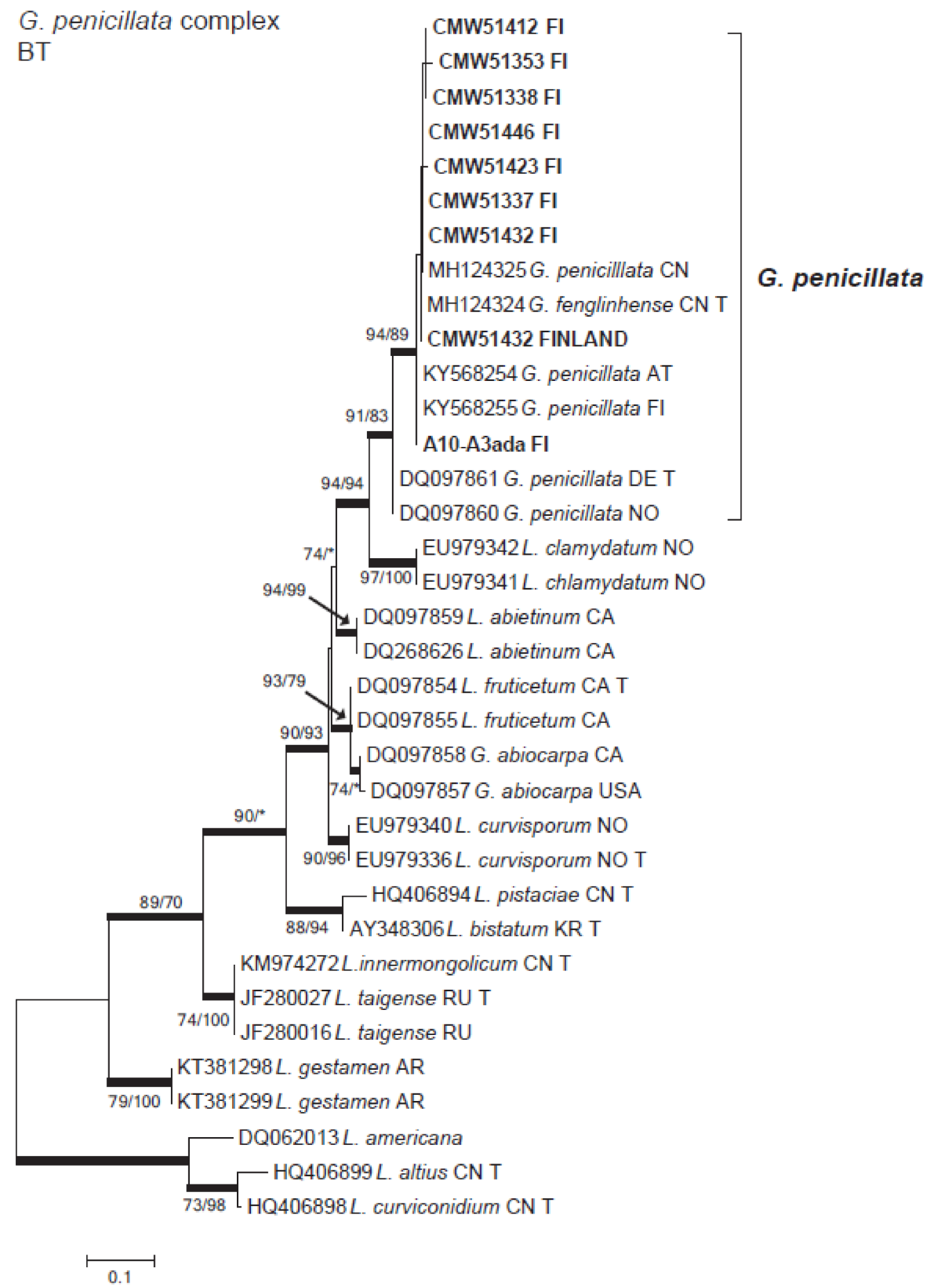

Figure 3. Phylogenetic tree of Grosmannia penicillata species complex obtained from maximum likelihood (ML) analyses of the $\beta$-tubulin (BT) data set. Sequences generated in this study are printed in bold type. Bootstrap values above $75 \%$ for ML/maximum parsimony (MP) are presented at the nodes. Posterior probabilities (above 90\%) obtained from Bayesian (BI) are indicated by bold lines at the relevant branching points. ${ }^{*}=$ bootstrap values $<75 \%$. $\mathrm{T}=$ ex-type isolates. Country abbreviations follow ISO 3166 Country Codes. Scale bar = total nucleotide difference between taxa. 


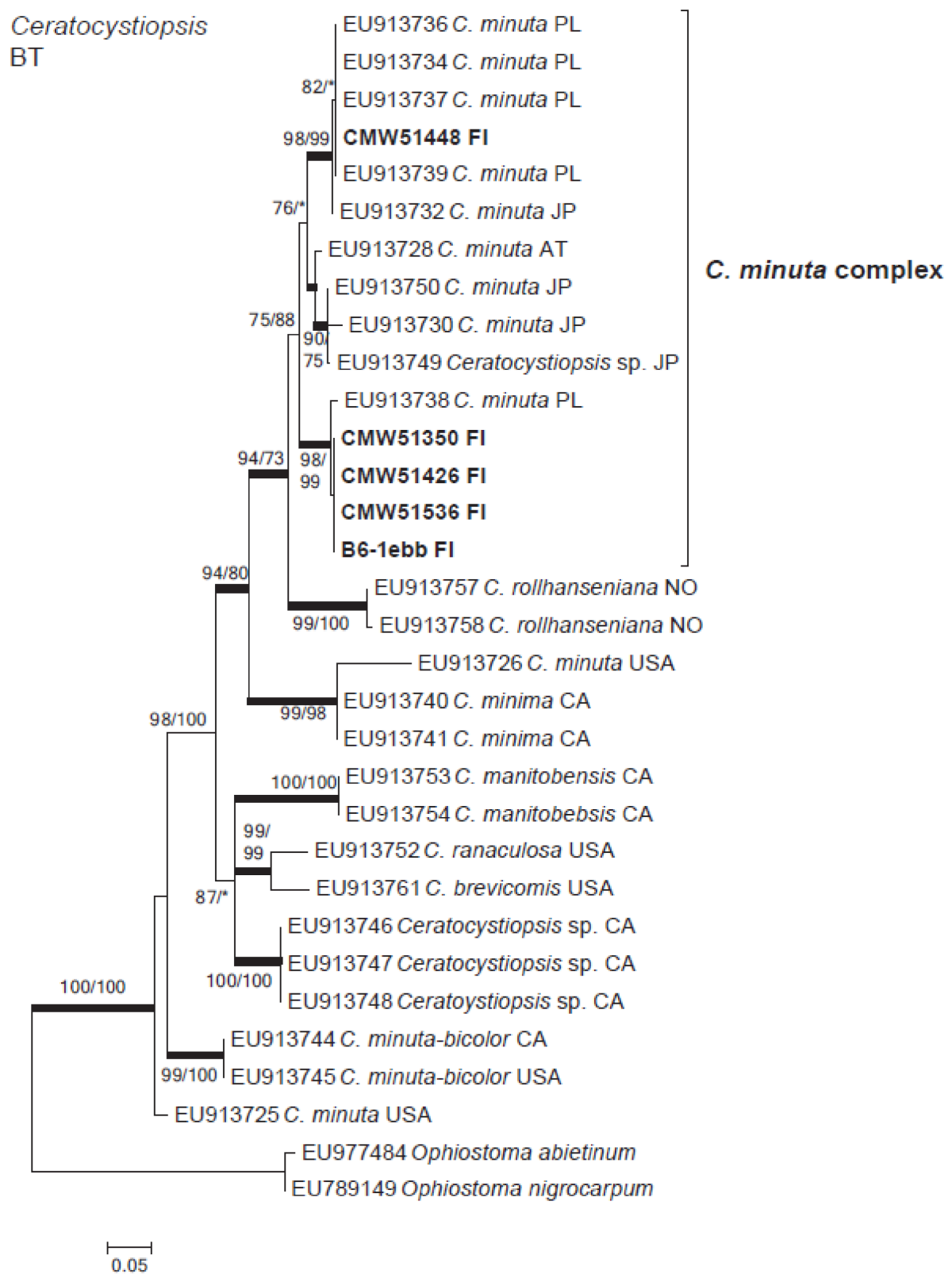

Figure 4. Phylogenetic tree of Ceratocystiopsis obtained from maximum likelihood (ML) analyses of the $\beta$-tubulin (BT) data set. Sequences generated in this study are printed in bold type. Bootstrap values above 75\% for ML/maximum parsimony (MP) are presented at the nodes. Posterior probabilities (above 90\%) obtained from Bayesian (BI) are indicated by bold lines at the relevant branching points. ${ }^{*}=$ bootstrap values $<75 \%$. T = ex-type isolates. Country abbreviations follow ISO 3166 Country Codes. Scale bar $=$ total nucleotide difference between taxa. 


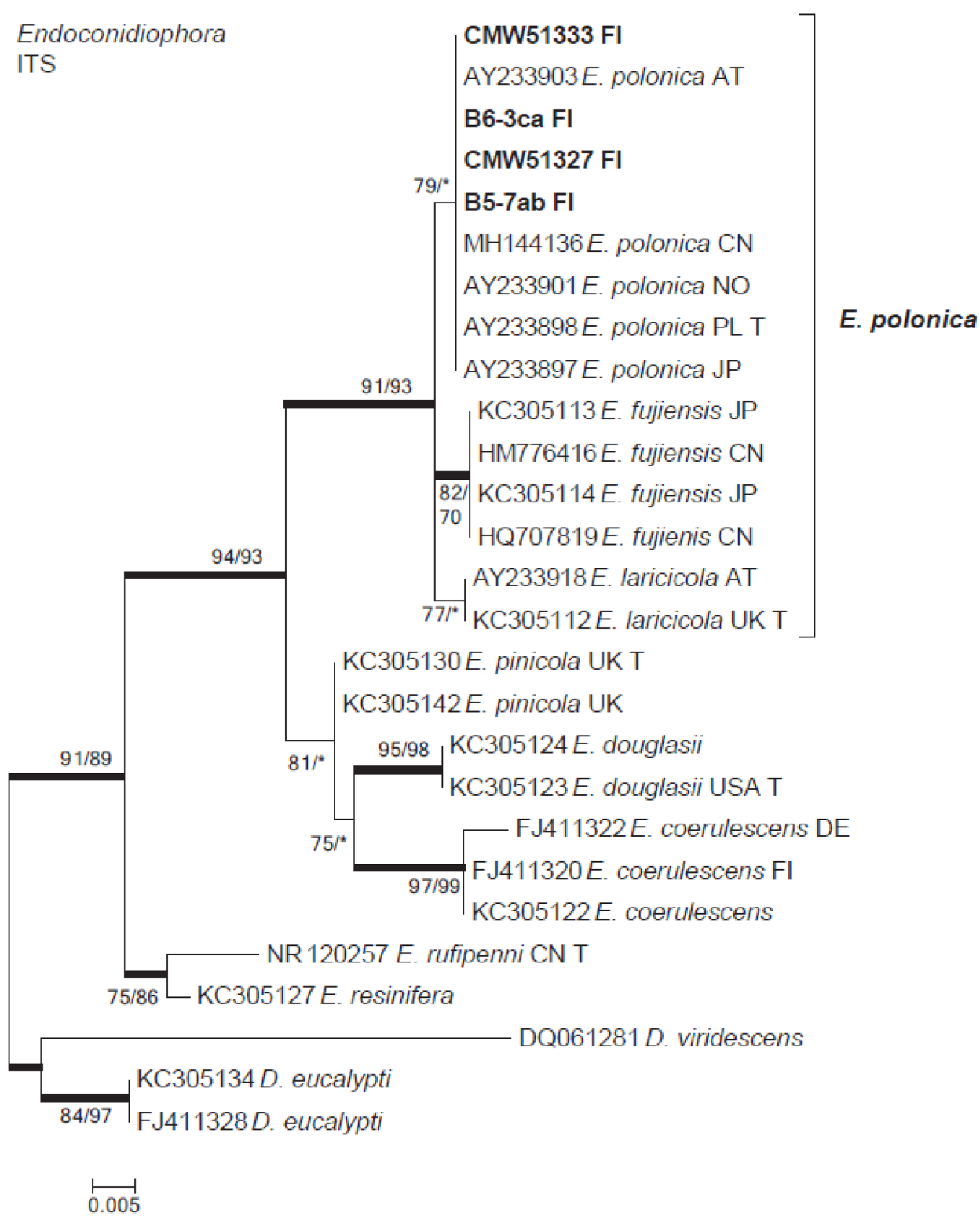

Figure 5. Phylogenetic tree of Endoconidiophora obtained from maximum likelihood (ML) analyses of the internal transcribed spacer region (ITS) data set. Sequences generated in this study are printed in bold type. Bootstrap values above $75 \%$ for ML/maximum parsimony (MP) are presented at the nodes. Posterior probabilities (above $90 \%$ ) obtained from Bayesian (BI) are indicated by bold lines at the relevant branching points. ${ }^{*}=$ bootstrap values $<75 \%$. T $=$ ex-type isolates. Country abbreviations follow ISO 3166 Country Codes. Scale bar = total nucleotide difference between taxa. 
Graphium

ITS

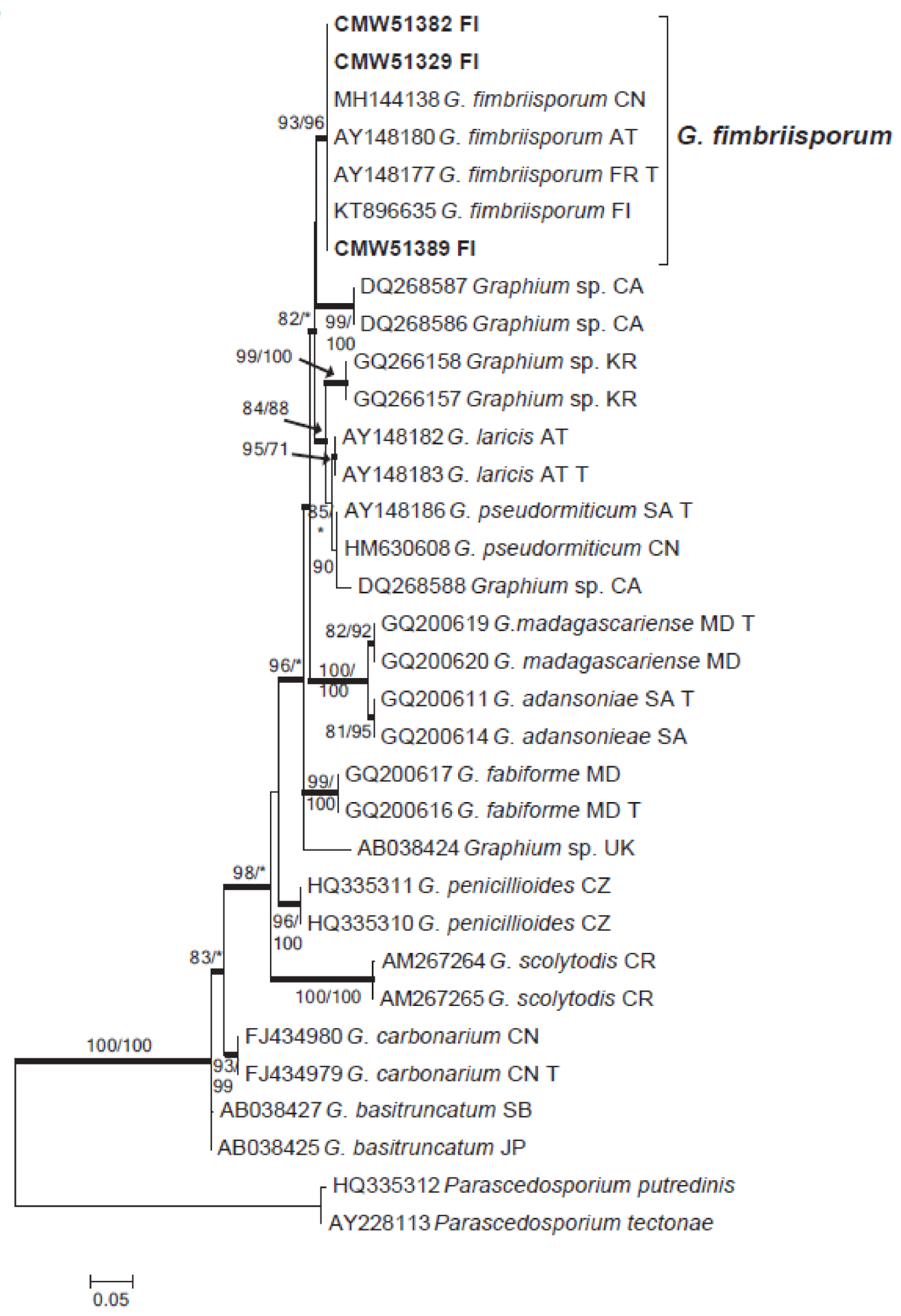

Figure 6. Phylogenetic tree of Graphium obtained from maximum likelihood (ML) analyses of the internal transcribed spacer region (ITS) data set. Sequences generated in this study are printed in bold type. Bootstrap values above $75 \%$ for ML/maximum parsimony (MP) are presented at the nodes. Posterior probabilities (above 90\%) obtained from Bayesian (BI) are indicated by bold lines at the relevant branching points. ${ }^{*}=$ bootstrap values $<75 \%$. $\mathrm{T}=$ ex-type isolates. Country abbreviations follow ISO 3166 Country Codes. Scale bar = total nucleotide difference between taxa. 


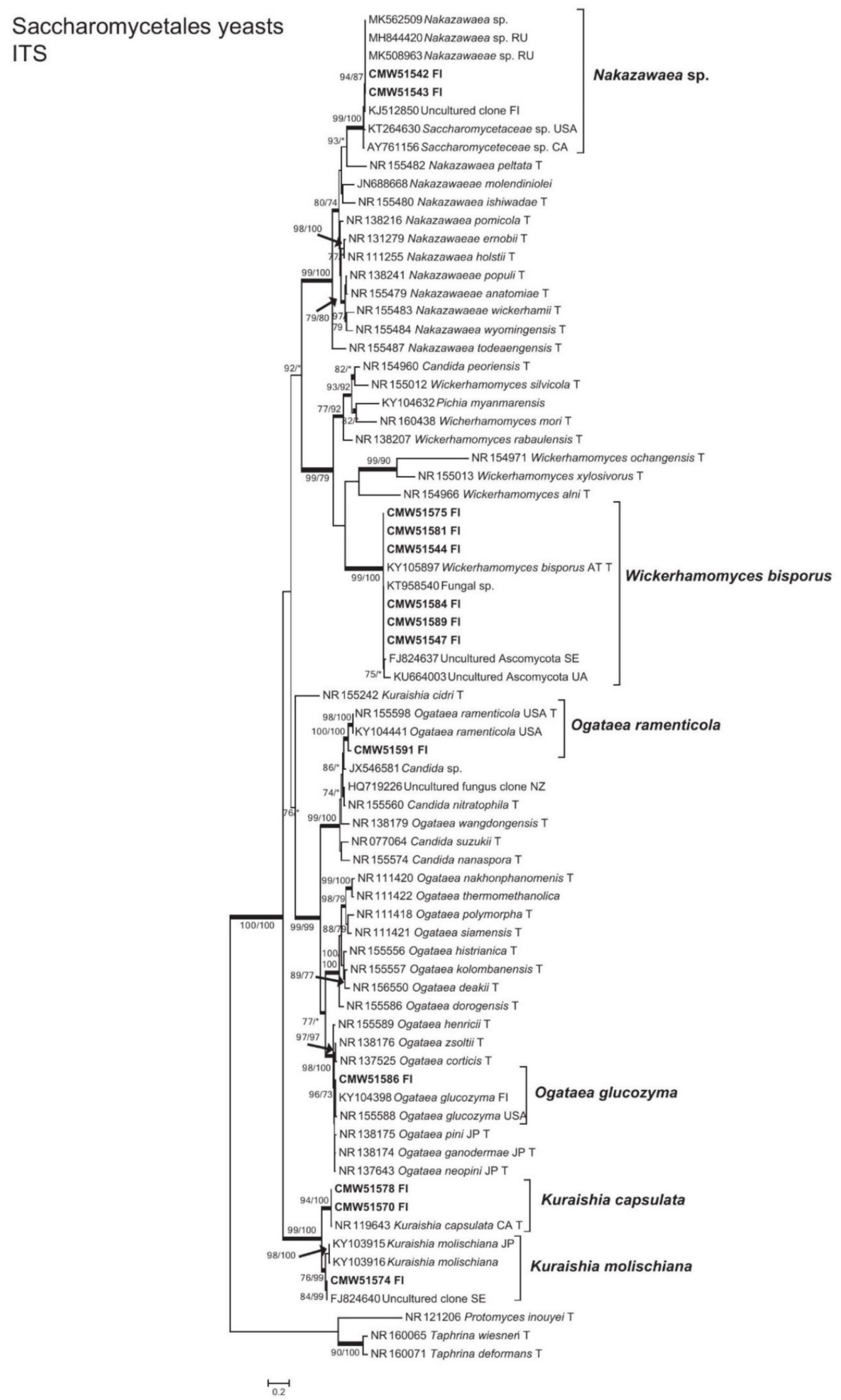

Figure 7. Phylogenetic tree of Saccharomycetales yeasts obtained from maximum likelihood (ML) analyses of the internal transcribed spacer region (ITS) data set. Sequences generated in this study are printed in bold type. Bootstrap values above $75 \%$ for ML/maximum parsimony (MP) are presented at the nodes. Posterior probabilities (above 90\%) obtained from Bayesian (BI) are indicated by bold lines at the relevant branching points. ${ }^{*}=$ bootstrap values $<75 \% . \mathrm{T}=$ ex-type isolates. Country abbreviations follow ISO 3166 Country Codes. Scale bar = total nucleotide difference between taxa. 


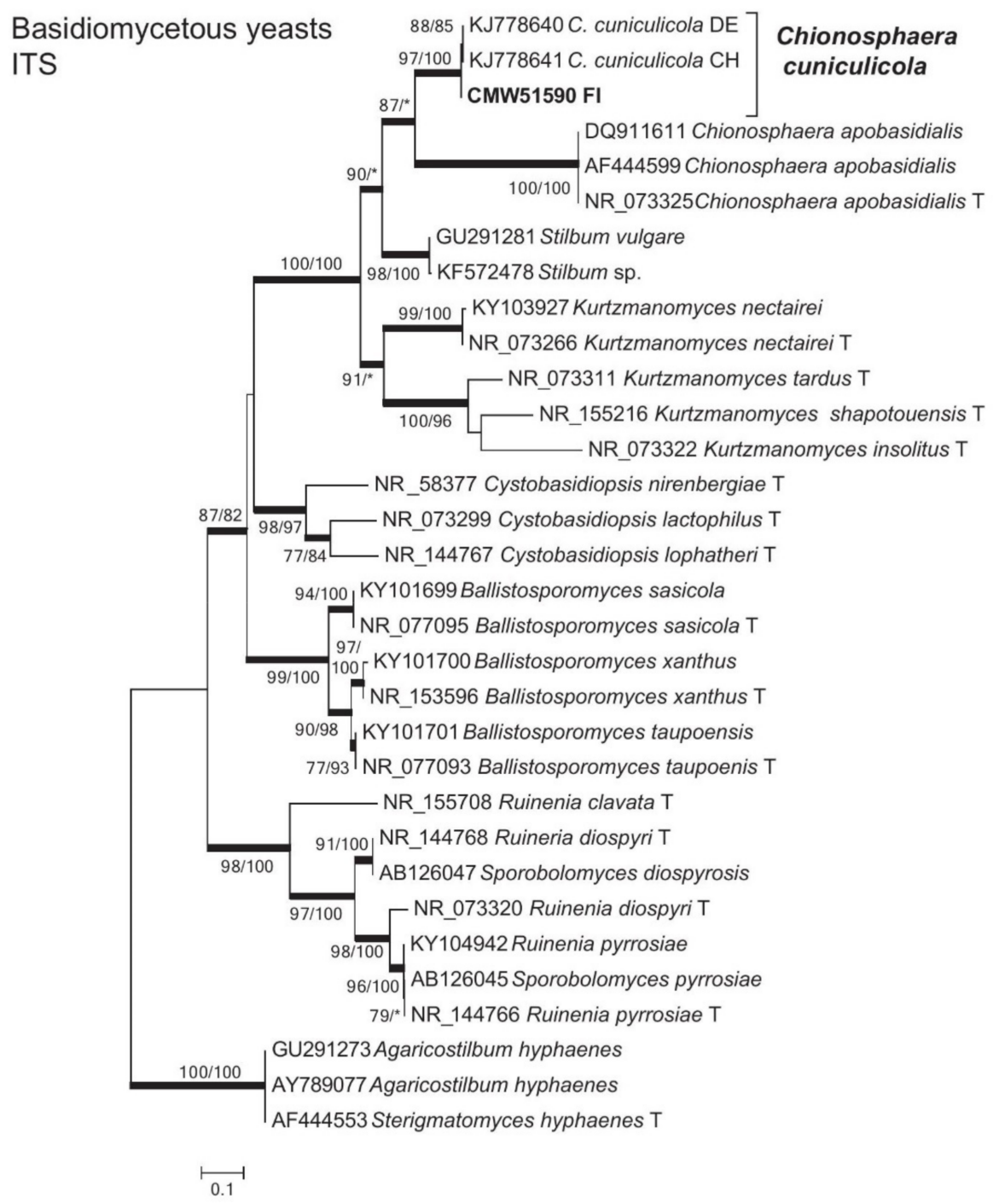

Figure 8. Phylogenetic tree of Basidiomycota yeasts obtained from maximum likelihood (ML) analyses of the internal transcribed spacer region (ITS) data set. Sequences generated in this study are printed in bold type. Bootstrap values above $75 \%$ for ML/maximum parsimony (MP) are presented at the nodes. Posterior probabilities (above 90\%) obtained from Bayesian (BI) are indicated by bold lines at the relevant branching points. ${ }^{*}=$ bootstrap values $<75 \%$. T $=$ ex-type isolates. Country abbreviations follow ISO 3166 Country Codes. Scale bar $=$ total nucleotide difference between taxa.

\subsection{Yeasts}

The Ascomycete yeasts included six species of Saccharomycetales (Figure 7) and a single yeast-like species (Fontanospora fusirasimosa) of uncertain taxonomic placement (Table 1). The most commonly found were isolates identified as Wickerhamomyces bisporus. They formed a well-supported clade with the ex-type isolate of W. bisporus and sequences from isolates and uncultured environmental sample sequences originating from bark beetles and their galleries, including I. typographus.

The other ascomycetous yeasts included two species of Ogataea and Kuraishia (Figure 7). The isolate representing Ogataea ramenticola grouped together with the ex-type isolate of the species. The other Ogataea species was closely related to Ogataea glucozyma. However, its identity requires further confirmation as several other Ogataea species grouped within the same phylogenetic clade. The Kuraishia species found in this study were identified as Kuraishia capsulata and Kuraishia molischiana. One putatively novel ascomycetous yeast species in the genus Nakazawaea was detected (Figure 7). The isolates obtained in this study grouped in 
a well-supported clade with the other bark beetle-derived sequence data from isolates or uncultured environmental samples originating from Finland, Russia and North America.

The single basidiomycetous yeast species was identified as Chionosphaera cuniculicola (Figure 8). It formed a well-supported phylogenetic clade with the other C. cuniculicola isolates originating from conifer-inhabiting beetles.

\section{Discussion}

This study contributes to limited research on fungi associated with mites phoretic on I. typographus. It is also the first to report yeasts associated with mites phoretic on I. typographus in Finland. In total, 145 fungal cultures representing 15 taxa were isolated, including seven filamentous fungi and eight yeasts or yeast-like species. The most common were the ophiostomatoid species residing in the Ophiostoma s. lat. and Leptographium s. lat. (Seifert et al. 2013). The most commonly detected ophiostomatoid species included G. penicillata, O. bicolor and species residing in the recently defined O. clavatum complex [14]. Of the yeast species, an ascomycetous yeast $W$. bisporus was the most frequently found.

Over thirty mite species, of which 15 phoretic, have been reported in association with I. typographus in Finland [5]. Based on Penttinen et al. (2013) study, the most abundant mites associated with the beetle are members of Mesostigmata, Oribata and Prostigmata. In the present study, the mites were morphologically identified as Uropodina (Mesostigmata). Mesostigmatic mites have also been reported as common I. typographus-associates in studies conducted in other European countries [40,41]. Unlike the case for I. typographus, very little is known regarding the relationships between mites and fungi. In this regard, [42] suggested that phoretic mites of Cerambycidae could be implicated in the transmission of fungi found in their galleries. Our results support the relatively limited previous studies where mites have commonly been found in association with ophiostomatoid fungi $[10,16-18,43]$. This is not particularly surprising, as these organisms (beetles, mites and fungi) share the same habitat and likely form complex, multi-partite interactions in the host tree galleries. However, certain fungal species have been more consistently reported in association with mites phoretic on I. typographus rather than with the beetles. Most notable of these is the presence of O. bicolor in Finland, Sweden and Japan [10,43,44]. Chang et al. [3] also hypothesized that this commonly found species could be predominantly a mite-associated fungus. Some of the mite species are mycetophagous $[20,21]$ and it is possible that $O$. bicolor is of nutritional importance to certain mites.

All the other ophiostomatoid species found in this study (O. ainoae, O. brunneolum, G. penicillata, Cop. minuta, E. polonica and Gr. fimbriisporum) have previously been reported in association with I. typographus in Europe [8-11,13,45]. A previous study has shown that the pathogenic fungus E. polonica is capable for the degradation of phenolic defense compounds of Norway spruce and thus may have an important role in the bark beetle ability to colonize trees [6]. Species in the O. clavatum complex are well-known associates of Ips species [14]. Two species, O. ainoae and O. brunneolum residing in this complex were detected in the present study. This is the first report of O. brunneolum in Finland. Cop. minuta found in this study is a fungus that has rarely been reported in Finland $[46,47]$ and its identity confirmed for the first time using DNA-based identification. The species remains a taxonomic challenge and appears to represent a cryptic species complex rather than a single species [48]. Cop. minuta isolates originating from the present study likely include two species for which the taxonomic boundaries remain to be resolved.

An interesting outcome of this study was the dominant presence of a number of yeast species existing in association with the phoretic mites. The yeast diversity in this habitat has received little attention, but recent studies have reported that yeasts are common bark beetle-associates that have only emerged as relevant after DNA sequencing techniques have been applied to taxonomic studies [49,50]. Consistent with the previous studies recently summarized by Davis [23], yeasts in the Saccharomycetaceae were the most frequently found also in this study. Wickerhamomyces bisporus was the most frequently isolated yeast and it has also been also previously found in association with I. typographus in Europe [50]. 
Species of Wickerhamomyces have been reported from galleries and guts of wood-boring insects [51,52], indicating their common association with beetles.

The other Saccharomycetaceae isolates included members of Ogataea, Kuraishia and Nakazawaea, which is consistent with the study of [53]. The common occurrence of these yeast genera as part of I. typographus mycobiome is also supported by the recent highthroughput sequencing study [24]. One of the species, K. capsulata, has been amongst the most commonly reported yeast species in surveys of I. typographus and other Ips species $[23,50,53,54]$. The Nakazawaea species detected in this study represents a putatively novel species, apparently common associate of I. typographus and other bark beetles, that remains to be formally described. The only basiodiomycetous yeast detected was $C$. cuniculicola. It was originally described as commonly associated with various bark beetle species, including I. typographus, in several locations in Europe [55]. It has also been found associated with the invasive pine-infesting beetle, Dendroctonus valens LeConte in China [56].

The results of this study highlight the fact that there remains much to learn regarding the intricate interactions of fungi, mites and other organisms associated with I. typographus. This despite the fact that it is an extensively studied example of bark beetle-microbial associations and as highlighted in the recent review of Biederman et al. (2020). Furthermore, mites phoretic on I. typographus are associated with rich fungal diversity, including yeasts that probably have functional roles in mite and bark beetle ecology.

Author Contributions: Conceptualization, R.L., T.A.D., R.K. and M.J.W.; methodology, R.L., I.L., O.-P.T., R.K. and T.A.D.; software, R.L., I.L and T.A.D.,.; validation, R.L and T.A.D.; formal analysis, R.L.; investigation, I.L., H.V., R.K.; resources, O.-P.T., T.J., M.J.W.; data curation, R.L.; writing-original draft preparation, R.L. and I.L.; writing—review and editing, R.L., I.L., P.V., O.-P.T., H.V., T.J., R.K., T.A.D., M.J.W.; visualization, R.L.; supervision, R.L., O.-P.T., H.V., R.K., T.A.D. and M.J.W.; project administration, R.L., H.V. and T.J.; funding acquisition, R.L., H.V., T.J. and M.J.W. All authors have read and agreed to the published version of the manuscript.

Funding: This study was financially supported by the members of the Tree Protection Co-operative Programme (TPCP) and the THRIP initiative of the Department of Trade and Industry, South Africa; the YeastsGoWild! - project and Developing monitoring and control of forest insect damage increasing with warming climate, particularly those caused by spruce bark beetles, Natural Resources Institute Finland (Luke).

Data Availability Statement: The sequence data generated in this study (accession numbers in Table 1) are openly available in GenBank (http:/ / www.ncbi.nlm.nih.gov).

Acknowledgments: Hanna Ruhanen, Moona Pahnik, Riku Kostamo, Riika Ryynänen and Ville Vesakoski are thanked for their field assistance. Saila Laine and Esa Laine are thanked for their technical assistance in the laboratory. We are grateful for the technical assistance that we have received from the Natural Resources Institute Finland (Luke), University of Eastern Finland, and Forestry and Agricultural Biotechnology Institute (FABI) during the study.

Conflicts of Interest: The authors declare that have no conflict of interest.

\section{References}

1. Neuvonen, S.; Viiri, H. Changing climate and outbreaks of forest pest insects in a cold northern country, Finland. In The Interconnected Arctic-UArctic Congress 2016; Latola, K., Savela, H., Eds.; Springer Polar Sciences: Cham, Switzerland, 2017.

2. Økland, B.; Netherer, S.; Marini, L. The Eurasian spruce bark beetle: The role of climate. In Climate Change and Insect Pests; Björkman, C., Niemelä, P., Eds.; CAB International: Wallingford, UK, 2015; pp. 202-219.

3. Chang, R.; Duong, T.; Taerum, S.; Wingfield, M.; Zhou, X.; Yin, M.; De Beer, Z. Ophiostomatoid fungi associated with the spruce bark beetle Ips typographus, including 11 new species from China. Persoonia Mol. Phylogeny Evol. Fungi 2019, 42, 50-74. [CrossRef] [PubMed]

4. Grucmanová, S.; Holuša, J. Nematodes associated with bark beetles, with focus on the genus Ips (Coleoptera: Scolytinae) in Central Europe. Acta Zool. Bulg. 2013, 65, 547-554.

5. Penttinen, R.; Viiri, H.; Moser, J. The mites (Acari) associated with bark beetles in the Koli national park in Finland. Acarologia 2013, 53, 3-15. [CrossRef] 
6. Kandasamy, D.; Gershenzon, J.; Andersson, M.N.; Hammerbacher, A. Volatile Organic Compounds Influence the Interaction of the Eurasian Spruce Bark Beetle (Ips Typographus) with Its Fungal Symbionts. ISME J. 2019, 13, 1788-1800. [CrossRef]

7. Seifert, K.A.; De Beer, Z.W.; Wingfield, M.J. (Eds.) The Ophiostomatoid Fungi: Expanding Frontiers; CBS: Utrecht, The Netherlands, 2013.

8. Jankowiak, R. Fungi associated with Ips typographus on Picea abies in southern Poland and their succession into the phloem and sapwood of beetle infested trees and logs. For. Pathol. 2005, 35, 37-55. [CrossRef]

9. Kirisits, T. Fungal associates of European bark beetles with special emphasis on the ophiostomatoid fungi. In Bark and Wood Boring Insects in Living Trees in Europe, a Synthesis; Lieutier, F., Day, K.R., Battisti, A., Gregoire, J.-C., Evans, H.F., Eds.; Springer: Amsterdam, The Netherlands, 2004; pp. 181-236.

10. Linnakoski, R.; Mahilainen, S.; Harrington, A.; Vanhanen, H.; Eriksson, M.; Mehtätalo, L.; Pappinen, A.; Wingfield, M.J. Seasonal succession of fungi associated with Ips typographus beetles and their phoretic mites in an outbreak region of Finland. PLoS ONE 2016, 11, e0155622. [CrossRef]

11. Viiri, H.; Lieutier, F. Ophiostomatoid fungi associated with the spruce bark beetle, Ips typographus, in three areas in France. Ann. For. Sci. 2004, 61, 215-219. [CrossRef]

12. Jankowiak, R.; Strzałka, B.; Bilański, P.; Kacprzyk, M.; Lukášová, K.; Linnakoski, R.; Matwiejczuk, S.; Misztela, M.; Rossa, R. Diversity of Ophiostomatales species associated with conifer-infesting beetles in Western Carpathians. Eur. J. For. Res. 2017, 136, 939-956. [CrossRef]

13. Linnakoski, R.; De Beer, Z.W.; Ahtiainen, J.; Sidorov, E.; Niemelä, P.; Pappinen, A.; Wingfield, M.J. Ophiostoma spp. associated with pine- and spruce-infesting bark beetles in Finland and Russia. Persoonia 2010, 25, 72-93. [CrossRef]

14. Linnakoski, R.; Jankowiak, R.; Villari, C.; Kirisits, T.; Solheim, H.; De Beer, Z.W.; Wingfield, M.J. The Ophiostoma clavatum species complex: A newly defined group in the Ophiostomatales including three novel taxa. Antonie van Leeuwenhoek 2016, 109, 987-1018. [CrossRef] [PubMed]

15. Biedermann, P.H.; Vega, F.E. Ecology and evolution of insect-fungus mutualisms. Annu. Rev. Entomol. 2020, 65. [CrossRef] [PubMed]

16. Chang, R.; Duong, T.A.; Taerum, S.J.; Wingfield, M.J.; Zhou, X.; de Beer, Z.W. Ophiostomatoid fungi associated with coniferinfesting beetles and their phoretic mites in Yunnan, China. MycoKeys 2017, 28, 19-64. [CrossRef]

17. Chang, R.; Duong, T.A.; Taerum, S.J.; Wingfield, M.J.; Zhou, X.; De Beer, Z.W. Ophiostomatoid fungi associated with mites phoretic on bark beetles in Qinghai, China. IMA Fung. 2020, 11. [CrossRef] [PubMed]

18. Vissa, S.; Hofstetter, R.W. The role of mites in bark and ambrosia beetle-fungal interactions. In Insect Physiology and Ecology; Shields, V., Ed.; InTech: Rijeka, Croatia, 2017; pp. 135-156.

19. Moser, J.C. Use of sporothecae by phoretic Tarsonemus mites to transport ascospores of coniferous bluestain fungi. Trans. Br. Mycol. Soc. 1985, 84, 750-753. [CrossRef]

20. Lombardero, M.J.; Klepzig, K.D.; Moser, J.C.; Ayres, M.P. Biology, demography and community interactions of Tarsonemus (Acarina: Tarsonemidae) mites phoretic on Dendroctonus frontalis (Coleoptera: Scolytidae). Agric. For. Entomol. 2000, 2, 193-202. [CrossRef]

21. Hofstetter, R.; Moser, J. The role of mites in insect-fungus associations. Annu. Rev. Entomol. 2014, 59, 537-557. [CrossRef]

22. Siemaszko, W. Zespoly grzbow towarzyszacych kornikom polskim. Planta Pol. 1939, 7, 1-54.

23. Davis, T.S. The ecology of yeasts in the bark beetle holobiont: A century of research revisited. Microb. Ecol. 2014, 69, 723-732. [CrossRef]

24. Chakraborty, A.; Modlinger, R.; Ashraf, M.Z.; Synek, J.; Schlyter, F.; Roy, A. Core mycobiome and their ecological relevance in the gut of five Ips bark beetles (Coleoptera: Curculionidae: Scolytinae). Front. Microbiol. 2020, 11. [CrossRef]

25. Kurtzman, C.D.; Fell, J.W.; Boekhout, T. (Eds.) The Yeasts: A Taxonomic Study; Elsevier: New York, NY, USA, 2011.

26. Gardes, M.; Bruns, T.D. ITS primers with enhanced specificity for basidiomycetes-application to the identification of mycorrhiza and rusts. Mol. Ecol. 1993, 2, 113-118. [CrossRef] [PubMed]

27. White, T.J.; Bruns, T.; Lee, S.; Taylor, J. Amplification and direct sequencing of fungal ribosomal RNA genes for phylogenetics. In PCR Protocols: A guide to Methods and Applications; Innis, M.A., Gelfand, D.H., Sninsky, J.J., White, T.J., Eds.; Academic Press: New York, NY, USA, 1990; pp. 315-321.

28. O'Donnel, K.; Cigelnik, E. Two divergent intragenomic rDNA ITS2 types within a monophyletic lineage of the fungus Fusarium are nonorthologous. Mol. Phylogenet. Evol. 1997, 7, 103-116. [CrossRef] [PubMed]

29. Glass, N.L.; Donaldson, G.C. Development of primer sets designed for use with the PCR to amplify conserved genes from filamentous ascomycetes. Appl. Environ. Microbiol. 1995, 61, 1323-1330. [CrossRef]

30. Kumar, S.; Stecher, G.; Tamura, K. MEGA7: Molecular Evolutionary Genetics Analysis Version 7.0 for Bigger Datasets. Mol. Biol. Evol. 2016, 33, 1870-1874. [CrossRef] [PubMed]

31. Katoh, K.; Standley, D.M. MAFFT multiple sequence alignment software version 7: Improvements in performance and usability. Mol. Biol. Evol. 2013, 30, 772-780. [CrossRef] [PubMed]

32. Guindon, S.; Dufayard, J.-S.; Lefort, V.; Anisimova, M.; Hordijk, W.; Gascuel, O. New Algorithms and Methods to Estimate Maximum-Likelihood Phylogenies: Assessing the Performance of PhyML 3.0. Syst. Biol. 2010, 3, 307-321. [CrossRef] [PubMed]

33. Lefort, V.; Longueville, J.-E.; Gascuel, O. SMS: Smart Model Selection in PhyML. Mol. Biol. Evol. 2017, 9, 2422-2424. [CrossRef] [PubMed] 
34. Sugiura, N. Further analysts of the data by akaike' s information criterion and the finite corrections. Commun. Stat. Theory Methos 1978, 1, 13-26. [CrossRef]

35. Anisimova, M.; Gascuel, T.D. Approximate likelihood-ratio test for branches: A fast, accurate, and powerful alternative. Syst. Biol. 2006, 55, 539-552. [CrossRef]

36. Swofford, D.L. PAUP* 4.0; Phylogenetic analysis using parsimony ( ${ }^{*}$ and other methods); Sinauer Associates: Sunderland, MA, USA, 2002.

37. Ronquist, F.; Huelsenbeck, J.P. MrBayes 3: Bayesian phylogenetic inference under mixed models. Bioinformatics 2003, 19, 1572-1574. [CrossRef]

38. Nylander, J.A.A. MrModeltest v2; Program distributed by the author; Evolutionary Biology Centre, Uppsala University: Uppsala, Sweden, 2004.

39. Rambaut, A. Figtree, a Graphical Viewer of Phylogenetic Trees. Available online: http://tree.bio.ed.ac.uk/software/figtree (accessed on 20 January 2021).

40. Gwiazdowicz, D.J.; Kamczyc, J.; Teodorowicz, E.; Błoszyk, J. Mite communities (Acari, Mesostigmata) associated with Ips typographus (Coleoptera, Scolytidae) in managed and natural Norway spruce stands in Central Europe. Cent. Eur. J. Biol. 2012, 7, 910-916. [CrossRef]

41. Manu, M.; Poliză, D.; Onete, M. Comparative analysis of the phoretic mites communities (Acari: Mesostigmata) associated with Ips typographus from natural and planted Norway spruce stands-Romania. Rom. Biotech. Lett. 2018, 23. [CrossRef]

42. Wingfield, M.J.; Garnas, J.R.; Hajek, A.; Hurley, B.P.; de Beer, Z.W.; Taerum, S.J. Novel and Co-Evolved Associations between Insects and Microorganisms as Drivers of Forest Pestilence. Biol Invasions 2016, 18, 1045-1056. [CrossRef]

43. Moser, J.C.; Perry, T.J.; Solheim, H. Ascospores hyperphoretic on mites associated with Ips Typographus. Mycol. Res. 1989, 93, 513-517. [CrossRef]

44. Moser, J.C.; Perry, T.J.; Furuta, K. Phoretic mites and their hyperphoretic fungi associated with flying Ips typographus japonicus Niijima (Col., Scolytidae) in Japan. J. Appl. Entomol. 1997, 121, 425-428. [CrossRef]

45. Solheim, H. Species of Ophiostomataceae isolated from Picea abies infested by the bark beetle Ips Typographus. Nord. J. Bot. 1986, 6, 199-207. [CrossRef]

46. Savonmäki, S. Tärkeimmät Kaarnakuoriaisten Mäntyyn ja Kuuseen Levittämät Sinistäjäsienilajit. Master's Thesis, Department of Plant Pathology, University of Helsinki, Helsinki, Finland, 1990.

47. Ahtiainen, J. The Blue-Stain Fungi Associated with the Spruce Bark Beetle (Ips typographus L.) in Lake Vodla Area in Eastern Russia. Master's Thesis, University of Joensuu, Joensuu, Finland, 2008.

48. Plattner, A.; Kim, J.-J.; Reid, J.; Hausner, G.; Lim, Y.W.; Yamaoka, Y.; Breuil, C. Resolving taxonomic and phylogenetic incongruence within species Ceratocystiopsis minuta. Mycologia 2009, 101, 878-887. [CrossRef]

49. Persson, Y.; Vasaitis, R.; Långström, B.; Öhrn, P.; Ihrmark, K.; Stenlid, J. Fungi vectored by the bark beetle Ips typographus following hibernation under the bark of standing trees and in the forest litter. Microb. Ecol. 2009, 58, 651-659. [CrossRef]

50. Giordano, L.; Garbelotto, M.; Nicolotti, G.; Gonthier, P. Characterization of fungal communities associated with the bark beetle Ips typographus varies depending on detection method, location, and beetle population levels. Mycol. Prog. 2012, 12, 127-140. [CrossRef]

51. Hui, F.-L.; Chen, L.; Chu, X.-Y.; Niu, Q.-H.; Ke, T. Wicherhamomyces mori sp. nov., an anamorphic yeast species found in the guts of wood-boring insect larvae. Int. J. Syst. Evol. Microbiol. 2013, 63, 1174-1178. [CrossRef]

52. Ninomiya, S.; Mikata, K.; Kajimura, H.; Kawasaki, H. Two novel ascomycetous yeast species, Wickerhamomyces scolytoplatypi sp. nov. and Cyberlindnerea xylebori sp. nov., isolated from ambrosia beetle galleries. Int. J. Syst. Evol. Microbiol. 2013, 63, $2706-2711$. [CrossRef]

53. Leufvén, A.; Nehls, L. Quantification of different yeasts associated with the bark beetle, Ips typographus, during its attack on a spruce tree. Microb. Ecol. 1986, 12, 237-243. [CrossRef] [PubMed]

54. Leufvén, A.; Bergström, G.; Falsen, E. Interconversion of verbenols and verbenone by identified yeasts isolated from the spruce bark beetle Ips typographus. J. Chem. Ecol. 1984, 10, 1349-1361. [CrossRef] [PubMed]

55. Kirschner, R.; Begerow, D.; Oberwinkler, F. A new Chionosphaera species associated with conifer inhabiting bark beetles*. Mycol. Res. 2001, 105, 1403-1408. [CrossRef]

56. Lou, Q.-Z.; Lu, M.; Sun, J.-. H Yeast diversity associated with invasive Dendroctonus valens killing Pinus tabuliformis in China using culturing and molecular methods. Microb. Ecol. 2014, 68, 397-415. [CrossRef] [PubMed] 